ORIGINAL ARTICLE

\title{
The role of serum insulin-like growth factor I (IGF-I) in neonatal outcome
}

\author{
A R Hayati, F C Cheah, J F Yong, A E Tan, W M Norizah
}

See end of article for authors' affiliations

.....................

Correspondence to: Professor A R Hayati, Department of Pathology, Histopathology Unit, Faculty of Medicine, Hospital University Kebangsaan Malaysia, Jalan Yaacob Latif, Bandar Tun Razak, 56000 Kuala Lumpur, Malaysia; hayati@mail.hukm. ukm.my

Accepted for publication 11 May 2004
J Clin Pathol 2004;57:1299-1301. doi: 10.1136/icp.2004.017566

Aims: To determine the role of serum insulin-like growth factor I (IGF-I) in predicting the occurrence of septal hypertrophic cardiomyopathy in infants of mothers with diabetes.

Methods/materials: In this prospective study, 100 pregnant women (50 with diabetes and 50 controls), matched for age and race, were studied. One intrapartum blood sample was taken at 28 weeks of gestation from both groups of mothers and another sample at delivery. All samples were analysed for maternal IGF-I by an enzyme linked immunosorbent assay method. A chest radiograph and an electrocardiogram were performed on the babies of the mothers with diabetes within the first 24 hours of life. An echocardiogram was performed in the first 3 days of life to look for septal hypertrophy and to measure the myocardial thickness.

Results: In the six cases of neonatal septal hypertrophic cardiomyopathy, all the mothers had greatly raised IGF-I concentrations of more than $400 \mathrm{ng} / \mathrm{ml}$ at the time of delivery compared with a mean (SD) of $302(25) \mathrm{ng} / \mathrm{ml}$ in control mothers.

Conclusions: In the present study a crude analysis revealed that increased IGF-I concentrations correlate with neonatal septal hypertrophic cardiomyopathy.
G estational diabetes is a common medical disorder in pregnancy. Poor control leads to increased maternal and neonatal morbidity and mortality. ${ }^{1}$ The control of hyperglycaemia involves a multidisciplinary approach and is often difficult to optimise. Even when biochemical tests and glucose control (using blood sugar profile, glycated haemoglobin, and fructosamine) are regarded as satisfactory, babies are often born with features characteristic of those born to mothers with diabetes, being large for gestational age with cherubic cheeks and hairy ears. Interestingly, newborn infants of mothers diagnosed as having impaired glucose tolerance in pregnancy, using World Health Organisation criteria, often have features of infants born to mothers with diabetes, and develop hypoglycaemia and other complications associated with poor control of maternal diabetes. Large for gestational age babies and fetal macrosomia complicate the delivery process, resulting in birth trauma and consequent increased perinatal morbidity, and even mortality. In addition, poor control of maternal diabetes is associated with severe and refractory hypoglycaemia and the occurrence of hypertrophic cardiomyopathy.

\section{"Insulin-like growth factor I has a major influence on fetal and postnatal growth"}

Unrecognised hypoglycaemia leads to brain damage, and hypertrophic cardiomyopathy may cause heart failure and cardiac arrhythmias in the affected newborn. Maternal hyperglycaemia causing fetal pancreatic $\beta$ cell hyperplasia and hyperinsulinaemia is believed to be an indirect cause of fetal macrosomia. Growth factors in relation to glucose homeostasis are believed to regulate fetal growth. Therefore, these growth factors can be used to predict maternal control of diabetes in pregnancy and subsequent neonatal outcome. ${ }^{2}$

Insulin-like growth factor I (IGF-I) has a major influence on fetal and postnatal growth. IGF-I has been found to correlate with the birth weight of babies of mothers with diabetes, and IGF-I reflects the insulin concentration.
Complete IGF-I deficiency results in severe intrauterine growth failure and postnatal growth failure, ${ }^{3-6}$ whereas fetal macrosomia is a complication encountered in mothers with diabetes.

IGF-I stimulates cell growth and may inhibit cell death in many tissues and organs. It affects the heart in several ways. It can increase the size of heart muscle and the ability of the muscle to contract and pump blood. ${ }^{7}$ The purpose of our study was to assess the association between IGF-I and neonatal outcome in the form of septal hypertrophy.

In this first part of our study, we investigated IGF-I concentrations, which reflect the diabetic control in the mother, and whether they are directly related to fetal macrosomia and the severity of hypertrophic cardiomyopathy. We also compared the concentrations of IGF-I at 28 weeks of gestation and at delivery. The birth weights of the infants were correlated with the IGF-I values.

\section{MATERIALS AND METHODS}

This was a hospital based case control study, in which 100 pregnant women from two groups were recruited from the obstetric and gynaecology clinic, Hospital Universiti Kebangsaan Malaysia. They consisted of 50 mothers with diabetes and 50 control women without diabetes, matched for age, parity, gestation, and ethnicity. Informed consent was obtained from each parent upon enrolment of both the mothers and babies.

One intrapartum blood sample was taken at 28 weeks of gestation from both groups of mothers and another sample at delivery. All samples were analysed for maternal IGF-I, by enzyme linked immunosorbent assay using the Diagnostic Systems Laboratories (DSL6300, Webster, Texas, USA) kit. A chest radiograph and an electrocardiogram were performed on the babies of the mothers with diabetes within the first 24 hours of life. An echocardiogram was performed in the first 3 days of life to look for septal hypertrophy and to measure

Abbreviations: IGF-I, insulin-like growth factor I 


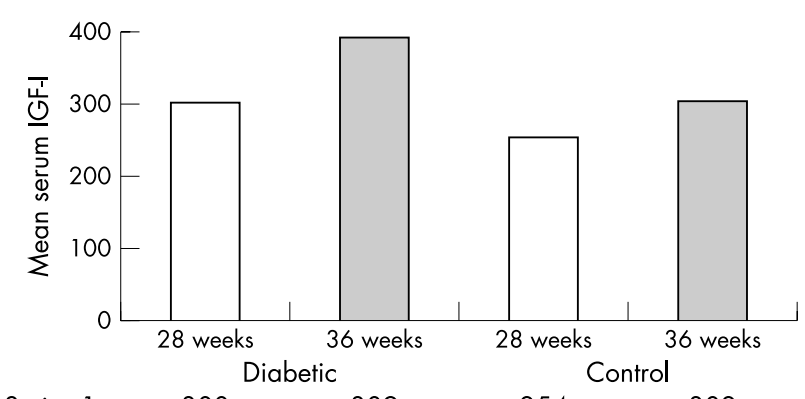

$\begin{array}{lllll}\text { Series } 1 & 300 & 389 & 254 & 302\end{array}$

Figure 1 Mean serum insulin-like growth factor (IGF-I) concentrations in mothers with diabetes and control mothers during two periods of gestation (28 weeks and 36 weeks).

the myocardial thickness. Signs of obstruction and the ejection fraction were also recorded.

\section{RESULTS}

The women recruited into our study were matched for their age, parity, gestation, and ethnicity. Of the 50 patients with diabetes during pregnancy, 25 had gestational diabetes mellitus, 15 patients had impaired glucose tolerance, and 10 patients had pre-existing diabetes mellitus.

Table 1 and fig 1 show details of the overall outcome of our study. Mothers with diabetes had significantly higher concentrations of serum IGF-I than the controls, both at 28 weeks and 36 weeks of gestation.

In our study, six mothers were found to have infants with neonatal septal hypertrophic cardiomyopathy (range, 6-11.5 mm; normal range, $3-4 \mathrm{~mm}$ ). There was a significant difference in IGF-I concentrations between the mothers of these infants and the control mothers $(p<0.01)$. The interventricular septum thicknesses of infants of control mothers fell within the normal range of 3-4 mm. All the six mothers who had infants with neonatal septal hypertrophic cardiomyopathy had greatly raised serum IGF-I concentrations of more than $400 \mathrm{ng} / \mathrm{ml}$ at the time of delivery, compared with a mean (SD) concentration of 302 (25) ng/ $\mathrm{ml}$ in the control mothers (fig 2).

\section{DISCUSSION}

IGF-I plays an important role in the control of fetal growth and development. ${ }^{4-6} 8-12$ Animal and in vitro evidence suggests that maternal IGF-I may have important effects on placental function..$^{13}$ Animal data suggest that maternal IGF-I influences fetal growth via effects on placental transfer, and maternal serum IGF-I has been shown to be low in fetal growth retardation. ${ }^{14}$ Similarly, we found low concentrations of IGF-I (IGF-I $<300 \mathrm{ng} / \mathrm{ml}$ ) in our very low birthweight infants (birth weight, $<1500 \mathrm{~g}$ ).

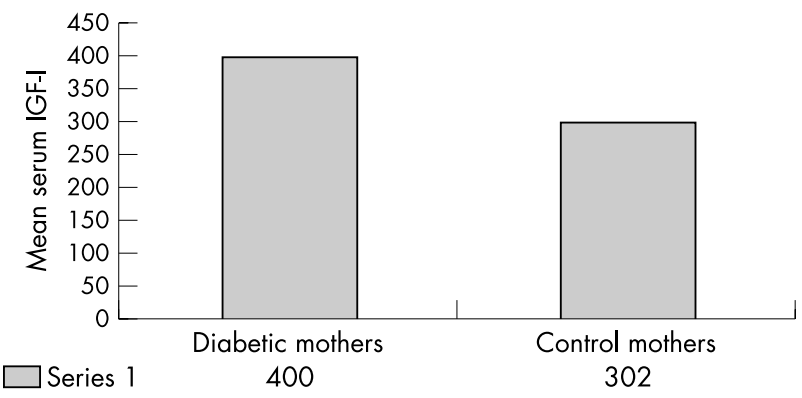

Figure 2 Mean serum insulin-like growth factor (IGF-I) concentrations in mothers with diabetes whose babies had neonatal septal hypertrophic cardiomyopathy and control mothers at the time of delivery.
Table 1 Mean (SD) serum IGF-I concentrations during two periods of gestation (28 weeks and 36 weeks)

\begin{tabular}{lll}
\hline \multicolumn{3}{l}{ Weeks of gestation } \\
\cline { 2 - 3 } 28 weeks & 36 weeks \\
\hline Mothers with diabetes & $300(18) \mathrm{ng} / \mathrm{ml}$ & $389(17) \mathrm{ng} / \mathrm{ml}$ \\
Control mothers & $254(18) \mathrm{ng} / \mathrm{ml}$ & $302(15) \mathrm{ng} / \mathrm{ml}$ \\
\hline
\end{tabular}

Infants of mothers with diabetes have an increased risk of developing congenital abnormalities, including hypertrophic cardiomyopathy, which features asymmetrical septal hypertrophy in most cases. ${ }^{15}$ Although the underlying mechanism for developing this condition is still unknown, septal hypertrophy usually regresses spontaneously. However, it is not known whether these infants are predisposed to ischaemic cardiomyopathy or sudden death earlier in life than other normal infants. In addition, severe cases of hypertrophic cardiomyopathy may present with heart failure or arrhythmia during the lst few days after birth. The electrocardiogram usually shows advanced left ventricular hypertrophy and abnormal Q waves in many leads as a result of septal hypertrophy. IGF-I is known to mediate many, if not most, of the anabolic effects of circulating growth hormone, including those in the heart. ${ }^{16}{ }^{17}$ Hypertrophic cardiomyopathy and abnormal ventricular diastolic filling in infants of mothers with diabetes are related to poor maternal glycaemic control. ${ }^{15}$

"In our six cases of neonatal septal hypertrophic cardiomyopathy, all the mothers had very high insulinlike growth factor I concentrations of more than $400 \mathrm{ng} /$ $\mathrm{ml}$ at the time of delivery"

Published data regarding the influence of serum IGF-I on birth weight and placental weight are not uniform, but several papers report positive correlations in both diabetic and non-diabetic pregnancies when focusing on third trimester IGF-I values. ${ }^{18-21}$

We found that serum IGF-I concentrations in maternal blood at delivery (36 weeks) were significantly higher than at 28 weeks of gestation in both groups, with concentrations being higher in the diabetic group than the control group. In our six cases of neonatal septal hypertrophic cardiomyopathy, all the mothers had very high IGF-I concentrations of more than $400 \mathrm{ng} / \mathrm{ml}$ at the time of delivery, compared with a mean (SD) of 302 (25) ng/ml in control mothers. Therefore, IGF-I appears to play a role in the development of neonatal septal hypertrophic cardiomyopathy.

The increasing concentrations of maternal serum IGF-I in mothers with diabetes up until the time of delivery may have influenced fetal growth and hence fetal weight. The

\section{Take home messages}

- High maternal concentrations of insulin-like growth factor I (IGF-I) at delivery are associated with neonatal septal hypertrophic cardiomyopathy, suggesting that high concentrations of IGF-I in late pregnancy play a role in the development of this condition

- Further studies are warranted to establish the role of IGF-I in the pathogenesis of neonatal septal hypertrophic cardiomyopathy 
extremely high maternal serum IGF-I concentrations during delivery in the six mothers whose babies had neonatal septal hypertrophic cardiomyopathy suggests that high concentrations of IGF-I in late pregnancy play a role in the development of this condition. These findings may form the basis for investigating the role of IGF-I in predicting neonatal outcome.

In conclusion, our study points towards an effect of IGF-I on fetal heart in diabetic pregnancies. Further studies are warranted to establish the role of IGF-I in the pathogenesis of neonatal septal hypertrophic cardiomyopathy.

\section{ACKNOWLEDGEMENTS}

The financial support of IRPA research grant 06-02-02-0128 is gratefully acknowledged.

\section{Authors' affiliations}

A R Hayati, F C Cheah, J F Yong, A E Tan, W M Norizah, Department of Pathology, Department of Paediatric and Department of Obstetric and Gynaecology, Faculty of Medicine, Hospital Universiti Kebangsaan Malaysia, Jalan Yaacob Latif, Bandar Tun Razak, 56000 Cheras, Kuala Lumpur, Malaysia

\section{REFERENCES}

1 Boo NY. Morbidity and mortality of infants of diabetic mothers at Maternity Hospital Kuala Lumpur. Med J Malaysia 1992;41:56-9.

2 Yan-Jun L, Tsushima T, Mind S, et al. Insulin-like growth factors (IGFs) and IGF-binding proteins (IGFBP-I, 2, and 3) in diabetic pregnancy: relationship to macrosomia. Endocr J 1996;43:221-31.

3 Linda BJ, Jovanna D, Juliane $N$, et al. Association between insulin like growth factor I (IGF-I) polymorphism, circulating IGF-I, and pre and postnatal growth in two European small for gestation age populations. J Clin Endocrinol Metab 2003;88:4805-10.

4 Baker J, Liu JP, Robertson EJ, et al. Role of insulin-like growth factors in embryonic and postnatal growth. Cell 1993;75:73-82.

5 Liu JP, Baker J, Perkins AS, et al. Mice carrying null mutations of the genes encoding insulin-like growth factor I (IGF-I) and type 1 IGF receptor (IGFIR). Cell 1993;75:59-72.

6 Woods KA, Camacho-Hubner C, Savage MO, et al. Intrauterine growth retardation and postnatal growth failure associated with deletion of the insulinlike growth factor I gene. N Engl J Med 1996;335:1363-7.
7 Vasan RS, Sullivan LM, D'Agostino RB, et al. Serum insulin-like growth factor I and risk for heart failure in elderly individuals without a previous myocardial infarction: the Framingham heart study. Ann Intern Med 2003;139:642-8.

8 Styne J. Fetal growth. Clin Perinatol 1998;25:917-38.

9 Giudice LC, de Zegher F, Gargosky SE, et al. Insulin-like growth factors and their binding proteins in the term and preterm human fetus and neonate with normal and extremes of intrauterine growth. J Clin Endocrinol Metab 1995:80:1548-55

10 Leger J, Noel M, Limal JM, et al. Growth factors and intrauterine growth retardation. II. Serum growth hormone, insulin-like growth factor (IGF) I, and IGF-binding protein 3 levels in children with intrauterine growth retardation compared with normal control subjects: prospective study from birth to two years of age, Study group of IUGR. Pediatr Res 1996;40:101-7.

11 Yakar S, Liu JL, Stannard B, et al. Normal growth and development in the absence of hepatic insulin-like growth factor I. Proc Natl Acad Sci U S A 1999;96:7324-9.

12 Lassarre C, Hardouin S, Daffos F, et al. Serum insulin-like growth factors and insulin-like growth factor binding proteins in the human fetus. Relationships with growth in normal subjects and in subjects with intrauterine growth retardation. Pediatr Res 1991;29:219-25.

13 Leger J, Oury JF, Noel M, et al. Growth factors and intrauterine growth retardation. I. Serum growth hormone, insulin-like growth factor (IGF)-I, IGFII, and IGF binding protein 3 levels in normally grown and growth-retarded human fetuses during the second half of gestation. Pediatr Res 1996:40:94-100.

14 Chard T, Howell RJS, Detection of fetal growth retardation by biochemical tests, In: Sharp F, Fraser RB, Milner RDG, eds. Fetal growth 1989:264-72.

15 Weber HS, Botti JJ, Baylen BG. Sequential longitudinal evaluation of cardiac growth and ventricular diastolic filling in fetuses of well controlled diabetic mothers. Pediatr Cardiol 1994; 15:184-9.

16 Kotlyar A-A, Vered Z, Goldberg I, et al. Insulin-like growth factor I and II preserve myocardial structure in postinfarct swine. Heart 2001;86:693-700.

17 Hikino S, Ihara K, Yamamoto J, et al. Physical growth and retinopathy in preterm infants: involvement of IGF-1 and GH. Pediatr Res 2001;50:732-6.

18 Caufriez A, Frankenne F, Hennen G, et al. Regulation of maternal IGF-I by placental GH in normal and abnormal human pregnancies. Am J Physiol 1993;265:E572-7.

19 Mclntyre HD, Serek R, Crane DI, et al. Placental growth hormone (GH), GHbinding protein, and insulin-like growth factor axis in normal, growthretarded, and diabetic pregnancies: correlations with fetal growth. J Clin Endocrinol Metab 2000;85:1143-50.

20 Lauszus FF, Klebe JG, Bek T, et al. Increased serum IGF-I during pregnancy is associated with progression of diabetic retinopathy. Diabetes 2003;52:852-6.

21 Lauszus FF, Klebe JG, Flyvbjerg A. Macrosomia associated with maternal serum insulin-like growth factor-I and -II in diabetic pregnancy. Obstet Gynecol 2001;97:734-41. 